\title{
Importance of Bcl-2-family proteins in murine hematopoietic progenitor and early $B$ cells
}

\author{
Constanze Kurschat ${ }^{1}$, Arlena Metz ${ }^{1}$, Susanne Kirschnek (D) ${ }^{1}$ and Georg Häcker (D) ${ }^{1,2}$ 凶
}

(c) The Author(s) 2021

\begin{abstract}
Mitochondrial apoptosis regulates survival and development of hematopoietic cells. Prominent roles of some Bcl-2-family members in this regulation have been established, for instance for pro-apoptotic Bim and anti-apoptotic Mcl-1. Additional, mostly smaller roles are known for other Bcl-2-members but it has been extremely difficult to obtain a comprehensive picture of the regulation of mitochondrial apoptosis in hematopoietic cells by Bcl-2-family proteins. We here use a system of mouse 'conditionally immortalized' lymphoid-primed hematopoietic progenitor (LMPP) cells that can be differentiated in vitro to pro-B cells, to analyze the importance of these proteins in cell survival. We established cells deficient in Bim, Noxa, Bim/Noxa, Bim/Puma, Bim/Bmf, Bax, Bak or Bax/Bak and use specific inhibitors of $\mathrm{Bcl}-2, \mathrm{Bcl}-\mathrm{X}_{\mathrm{L}}$ and $\mathrm{Mcl}-1$ to assess their importance. In progenitor (LMPP) cells, we found an important role of Noxa, alone and together with Bim. Cell death induced by inhibition of Bcl-2 and Bcl- $X_{L}$ entirely depended on Bim and could be implemented by Bax and by Bak. Inhibition of $\mathrm{Mcl}-1$ caused apoptosis that was independent of Bim but strongly depended on Noxa and was completely prevented by the absence of Bax; small amounts of anti-apoptotic proteins were coimmunoprecipitated with Bim. During differentiation to pro-B cells, substantial changes in the expression of Bcl-2-family proteins were seen, and $\mathrm{Bcl}-2, \mathrm{Bcl}-\mathrm{X}_{\mathrm{L}}$ and $\mathrm{Mcl}-1$ were all partially in complexes with Bim. In differentiated cells, Noxa appeared to have lost all importance while the loss of Bim and Puma provided protection. The results strongly suggest that the main role of Bim in these hematopoietic cells is the neutralization of $\mathrm{Mcl}-1$, identify a number of likely molecular events during the maintenance of survival and the induction of apoptosis in mouse hematopoietic progenitor cells, and provide data on the regulation of expression and importance of these proteins during differentiation along the $B$ cell lineage.
\end{abstract}

Cell Death and Disease (2021)12:784; https://doi.org/10.1038/s41419-021-04079-8

\section{INTRODUCTION}

Mitochondrial apoptosis regulates many biological processes and is very important for differentiation and regulation of survival in hematopoietic cells [1]. Mitochondrial apoptosis is regulated by the Bcl-2-family, comprising three groups of proteins that can be distinguished by their structure and by their function. The proapoptotic group of Bax and Bak serve as the effectors, initiating the activation of effector caspases in the cytosol. The five antiapoptotic proteins, $\mathrm{BCl}-2, \mathrm{BCl}-\mathrm{X}_{\mathrm{L}}, \mathrm{BCl}-\mathrm{W}, \mathrm{Mcl}-1$ and $\mathrm{A} 1$, inhibit apoptosis by binding pro-apoptotic family proteins. The third group, known as $\mathrm{BH} 3$-only proteins and made up by eight members, are the initiators of apoptosis. $\mathrm{BH} 3$-only proteins trigger apoptosis through one of two mechanisms, by inhibiting antiapoptotic Bcl-2-proteins and/or directly activating Bax/Bak. At least three BH3-only proteins, Bim, tBid (the active form of Bid) and Puma, can directly activate, while all $\mathrm{BH} 3$-only proteins (including Noxa, Bad, Bmf, Bik and Hrk) can inhibit anti-apoptotic Bcl-2-proteins [1, 2].

These basic operative principles of mitochondrial apoptosis seem unequivocal. It has however been notoriously difficult to move towards a detailed understanding of the events of the initiation of apoptosis and the chain of events from the receipt of a pro-apoptotic stimulus, over the activation of one or more $\mathrm{BH} 3$ only proteins and over the potentially necessary neutralization of anti-apoptotic Bcl-2 proteins to the activation of Bax or Bak or both. It is experimentally extremely challenging to control for the multitude of proteins and potential activation steps. Very likely, the apoptotic process is further regulated differently in different cell types. Gene-deletion experiments with mice and analysis of cell populations in physiological or near-physiological conditions have provided information on the roles of $\mathrm{Bcl}-2$-family proteins, for instance by measuring cell differentiation and population size in vivo or by testing of apoptosis induced by lack of signaling input in vitro. Cell biological and biochemical studies mostly in tumor cell lines have yielded results in terms of interaction between $\mathrm{Bcl}$-2-family members and sometimes activation studies. The relatively recent development of specific inhibitors of antiapoptotic Bcl-2-members has facilitated the study of mitochondrial apoptosis.

Mitochondrial apoptosis is a major regulator of homeostasis of immune cell populations [3]. Loss of individual anti-apoptotic proteins causes cell death in some cell populations [4], and at least some Bcl-2-like proteins can compensate for each other [5]. In terms of BH3-only proteins, the loss of Bim has the most severe

\footnotetext{
${ }^{1}$ Faculty of Medicine, Institute of Medical Microbiology and Hygiene, Medical Center, University of Freiburg, Freiburg, Germany. ${ }^{2}$ BIOSS Centre for Biological Signalling Studies, University of Freiburg, Freiburg, Germany. ${ }^{\circledR}$ email: georg.haecker@uniklinik-freiburg.de Edited by Kristopher Sarosiek
} 
effect, leading to enhanced apoptosis resistance in several cell types $[6,7]$. Some role has also been attributed to other BH3-only proteins, and loss of Puma [8], Bmf [9] or Noxa [10,11] on a Bimnegative background has been found to have varying effects. The knowledge of the exact molecular function of $\mathrm{Bcl}-2$-family proteins and how they neutralize or activate other family members to trigger apoptosis is far from comprehensive.

In this study, we endeavored to obtain information on the role of $\mathrm{Bcl}$-2-family proteins in mouse lymphoid-primed hematopoietic progenitor cells (LMPP) and cells differentiating from these progenitors towards the B cell lineage. LMPP represent a stadium of hematopoietic differentiation, of committed progenitors with both myeloid and lymphoid potential [12]. We use a system of 'conditionally immortalized' mouse LMPP, which on one hand behave very similarly to primary cells [13] and which, on the other hand, permit the cell biological study of mitochondrial apoptosis. We use cells deficient in pro-apoptotic Bcl-2-family proteins or in $\mathrm{Bax} / \mathrm{Bak}$, and employ $\mathrm{Bcl}$-2-protein inhibitors to test for the role of these components in apoptosis regulation and to probe some $\mathrm{Bcl}-$ 2-protein family interactions. We follow the differentiation to early $B$ cells in vitro, monitor protein-expression and their changing importance during differentiation.

\section{RESULTS \\ Contribution of BH3-only proteins to apoptotic signals in FLT3-progenitor lines}

Hoxb8 is a homeobox family protein that can increase self-renewal and arrest differentiation in hematopoietic cells [14]. A Hoxb8variant that is fused to the ligand binding domain of the estrogenreceptor can be turned on and off by adding or washing away estrogen [15]. When this construct is expressed in mouse hematopoietic progenitor cells, they can be expanded in the presence of estrogen while taking away estrogen, i.e., turning off Hoxb8, induces their differentiation. Depending on the growth factor added during initial establishment of the progenitor lines, cells can be generated that are committed to macrophage or neutrophil lineages [15] or that maintain both myeloid and lymphoid differentiation potential (termed multipotent progenitor (MPP) cells or lymphoid-primed MPP (LMPP) cells [13]; these cells are expanded in FLT3-ligand (FLT3L) and will here be referred to as FL-P cells).

We established FL-P cell lines, wt and with deficiency in proapoptotic Bcl-2-family proteins, by transducing bone marrow from the respective gene-deficient mice with the Hoxb8-ER construct and expanding the cells in medium containing FLT3L. We established FL$\mathrm{P}$ lines deficient in Noxa, in Bim or in Bim plus one of the $\mathrm{BH}$-only proteins Puma, Noxa or Bmf. The anti-apoptotic proteins $\mathrm{BCl}-\mathrm{X}_{\mathrm{L}}, \mathrm{BCl}-2$ and $\mathrm{Mcl}-1$ were easily detectable in the cell lines, and there was little difference between the cells of the various genotypes with the exception of higher Mcl-1-levels in Noxa-deficient cells (Supplementary Fig. S1A). These higher levels were seen in both Noxa-single and Bim/Noxa-double-deficient cells and were not surprising because Noxa is a known antagonist of $\mathrm{Mcl}-1$ and induces its proteasomal degradation [16]. Bim was easily detectable by western blotting, and the Bim levels in FL-P cells were slightly higher than in MEFs (Supplementary Fig. S1B), while Puma was clearly more highly expressed in FLP cells than in MEFs (Supplementary Fig. S1C). Mouse Noxa is not easily detectable by western blotting but we did obtain a signal in FLP cells, where expression was somewhat lower than in committed Hoxb8 neutrophil progenitor cells (Supplementary Fig. S1D). We were unable to detect Bmf by western blotting in LMPP. FL-P cells underwent apoptosis upon treatment with the topoisomerase II-inhibitor etoposide. Bim-deficiency provided some protection, additional loss of Bmf had no effect but additional loss of Puma did. Noxa-deficient cells showed substantial protection, and Bim/Noxa double-deficient cells were strongly protected (Supplementary Fig. S2A, B). This pattern reflects the expected roles of BH3-

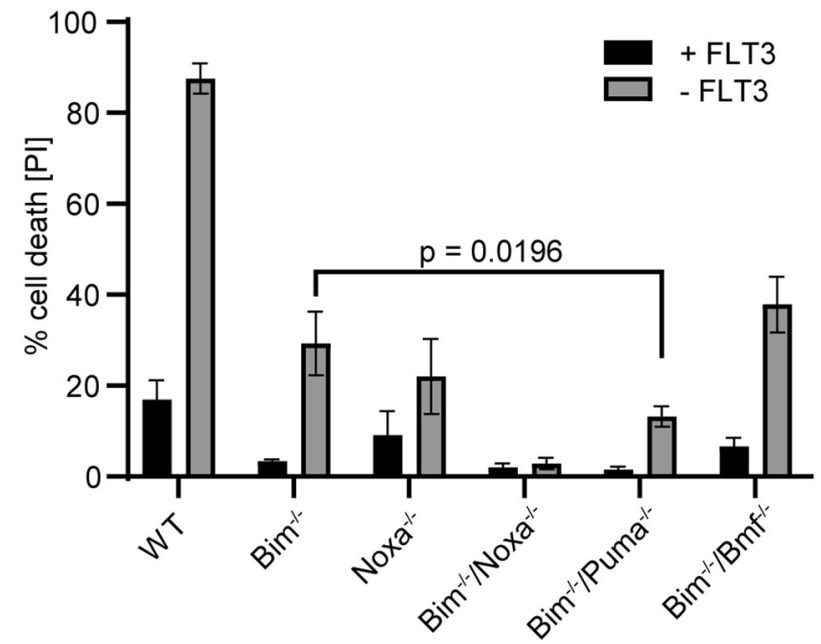

Fig. 1 Role of BH3-only proteins in factor-withdrawal-induced apoptosis in FL-P cells. FL-P cells of the indicated genotypes were incubated in the presence or absence of growth factor (FLT3L) for $14 \mathrm{~h}$, and cell viability was assessed by propidium iodide staining and flow cytometry. Shown are the mean values/SD of dead cells in three independent experiments; significance was tested by unpaired $t$-test.

only proteins in DNA-damage induced apoptosis. The loss of either Bax or Bak provided no protection but in the absence of both Bax and Bak, cells were completely protected against apoptosis (evidenced by the appearance of active caspase-3) and cell death (Supplementary Fig. S2C-F).

FL-P cells are cultured in FLT3L and die rapidly upon its withdrawal. Wt cells showed about $50 \%$ of cell death at $8 \mathrm{~h}$ and $90 \%$ cell death by $14 \mathrm{~h}$ post-withdrawal (Fig. 1, Fig. S2G, H). Bimdeficient cells were substantially protected. Additional lack of Bmf afforded no additional protection. Loss of Puma on a Bim-deficient background did provide additional protection. Isolated loss of Noxa reduced apoptosis strongly, with cells deficient in Bim and Noxa showing hardly any apoptosis upon factor-withdrawal (Fig. 1). Upon growth factor withdrawal, Mcl-1-levels decreased. In the absence of Noxa, Mcl-1-protein started at higher levels and did not disappear as quickly. There was no clear increase in Bimand a small, inconsistent increase in Puma-levels in these experiments (Supplementary Fig. S3). As has been recognized for other immune cell populations, Bim is thus important in FL-P cells but Noxa makes a substantial contribution to apoptosis in the situations tested here, and this Noxa-effect likely operates through antagonism of $\mathrm{Mcl}-1$.

\section{The role of $\mathrm{BH}$-only proteins in cell death induced by $\mathrm{Bcl}-2$ - family inhibitors}

We inhibited individual $\mathrm{BCl}$-2-proteins alone or in combination and tested the role of $\mathrm{BH} 3$-only proteins. A number of small molecules have been developed, which variably inhibit the main antiapoptotic proteins. The Bcl-2-specific inhibitor ABT-199 [17] showed high activity and induced cell death at low concentrations (about $40 \%$ cell death at 50 nM; Fig. 2, Supplementary Fig. S4), but higher concentrations had only very moderate additional effects. Only at concentrations of 2-10 $\mu \mathrm{M}$, cell death increased further substantially (Supplementary Fig. S4A). The pro-apoptotic activity at concentrations up to $2 \mu \mathrm{M}$ was almost entirely lost in the absence of either Bim or Noxa. At high concentrations, cells of all genotypes died although there was still reduced sensitivity in cells lacking the combination of either Bim and Noxa or Bim and Puma. Cell death completely depended on the presence of either Bax or 
A

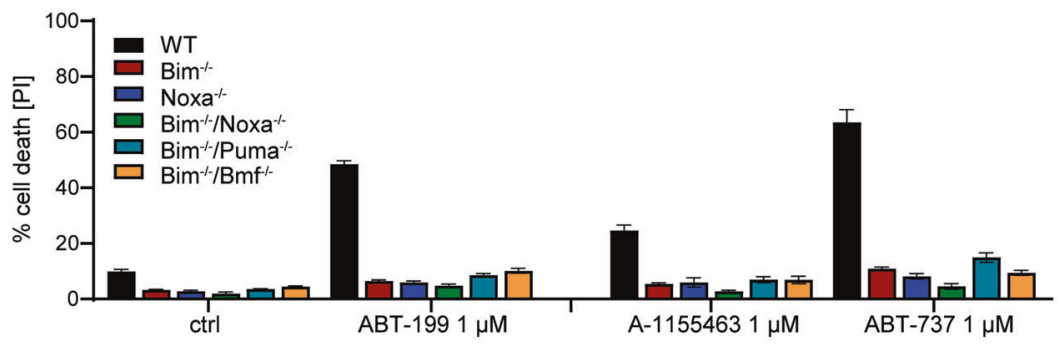

B

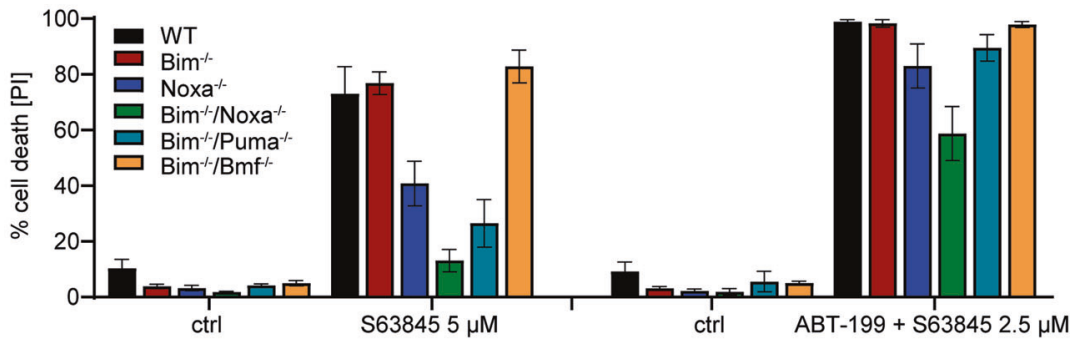

Fig. 2 Importance of individual BH3-only proteins in apoptosis induced by inhibition of anti-apoptotic Bcl-2-family proeins. FL-P cells of the indicated genotypes were treated with the indicated $\mathrm{Bcl}-2$-family inhibitors at different concentrations or combinations for $24 \mathrm{~h}$ as indicated; controls were cells incubated with equal concentrations of solvent (DMSO). In the combination with S63845, ABT-199 was used at $1 \mu \mathrm{M}$. Cells were analyzed by staining with propidium iodide and flow cytometry, and percentages of dead cells were calculated. Data are means/SD of three (A) or five (B) independent experiments. Data are individual points of the titrations shown in Supplementary Fig. S4.

Bak as cells double deficient in Bax and Bak were protected (Supplementary Fig. S4A). It seems likely that ABT-199 at high concentrations also neutralizes other anti-apoptotic Bcl-2-family proteins, as has been shown for $B c l-X_{L}$ [17]. Inhibition of $B c l-X_{L}(A-$ 1155463 [18]) had only a small effect (Fig. 2A). The combination of $\mathrm{BCl}-\mathrm{X}_{\mathrm{L}}$-inhibitor and $\mathrm{ABT}-199$ (together inhibiting both $\mathrm{BCl}-2$ and $\mathrm{Bcl}-\mathrm{X}_{\mathrm{L}}$ ) was roughly additive (Supplementary Fig. S2B), and a very similar result was seen when both anti-apoptotic proteins were inhibited with ABT-737 (Fig. 2,Supplementary Fig. S4C). In all cases, the loss of Bim almost completely protected against apoptosis induced by these inhibitors (Fig. 2, Supplementary Fig. S4; the effect of Bim-loss at later time points is shown in Supplementary Fig. S4H-K). The detection of cells harboring active caspase-3 upon inhibitor treatment correlated with annexin V/PI-staining, and the combined loss of Bax and Bak abrogated the appearance of both stains (Supplementary Fig. S5). There was no appreciable change in the levels of the detectable anti-apoptotic Bcl-2-family proteins during treatment with ABT-737 (not shown). Blocking Bcl2 and $\mathrm{BCl}-\mathrm{X}_{\mathrm{L}}$ (and $\mathrm{BCl}-\mathrm{w}$ ) at the same time therefore is a strong proapoptotic stimulus in $\mathrm{FL}-\mathrm{P}$, with $\mathrm{Bcl}-2$ being more important. This form of apoptosis critically depends on both Noxa and Bim. This suggests that Bim is in these cells normally sequestered by mostly $\mathrm{Bcl}-2$ and to a lesser degree by $\mathrm{Bcl}-\mathrm{X}_{\mathrm{L}}$. Noxa most likely acts by regulating the abundance of $\mathrm{Mcl}^{-1}$ [19]: in the absence of Noxa, active Bim is probably not sufficient to overcome the antiapoptotic effect of $\mathrm{Mcl}-1$.

Because at least most mammalian cells die when $B c l-2 / B c l-X_{L}$ and $\mathrm{Mcl}-1$ are inhibited, this suggested that an essential function of Bim was the neutralization of $\mathrm{Mcl}-1$, upon displacement from $\mathrm{Bcl}-2$. Consistent with this interpretation, inhibition of $\mathrm{Mcl}-1$ (using S63845 [20]) induced cell death that was Bim-independent. Loss of Noxa provided some protection, presumably through the higher Mcl-1-levels, and the combined loss of Bim and Noxa or Bim and Puma protected the cells substantially (Fig. 2B, Supplementary Fig. S4D). Combination treatments with ABT-199/737 and S63945 were also consistent with the interpretation that Bim was required for Mcl-1-neutralization: increasing concentrations of the Mcl-1- inhibitor increasingly removed the requirement for Bim (Fig. 2B, Supplementary Fig. S4E). We further tested for the individual requirement of Bax and Bak. Upon ABT-737-treatment, loss of either alone provided no protection (Fig. 3A). Because this form of apoptosis depends on Bim, this suggests that Bim can in these cells activate both proteins, either through antagonizing $\mathrm{Mcl}-1$ or through direct activation. Intriguingly, Mcl-1-antagonism-induced apoptosis received some contribution from Bak but was entirely dependent on Bax (Fig. 3B, Supplementary Figs. S4F, G, S4H-M for later time points). In this situation, Noxa contributes suggesting that $\mathrm{Mcl}-1$ can block both Bax and Bak. Because this form of apoptosis also requires Puma (presumably together with Bim), the results further indicate that Puma can activate Bax but not Bak in this situation; this may be the result of a reduced availability or ability of anti-apoptotic proteins to inhibit Bax.

We then tested binding of Bim to anti-apoptotic Bcl-2-proteins by immunoprecipitation. Bim was precipitated efficiently; although $\mathrm{MCl}-1, \mathrm{BCl}-2$ and $\mathrm{BCl}-\mathrm{X}_{\mathrm{L}}$ were all found in the IP-product to some extent, a very substantial part of these proteins remained in the supernatant (Fig. 3C). Inclusion of ABT-737 or S63845 shifted Bim away from the respective targets and to the untargeted binding partners although this shift was incomplete (Fig. 3C).

\section{Dynamics of Bcl-2-family expression during early B cell differentiation}

We used the Hoxb8-model to differentiate the LMPP (FL-P) cells to early B cells (here termed FL-D cells). Because it was difficult to separate the cell populations for our purposes, we replaced the OP9feeder cells of the original protocol [13] with the soluble factors FLT3L, IL-7 and SCF. When transplanted into mice, FL-P-cells differentiate into fully mature $B$ cells that have been re-isolated from the spleen. By about day 11 after Hoxb8-inactivation, most cells expressed markers of pro-B cells $\left(\mathrm{CD} 19^{+} \mathrm{B} 22 \mathrm{O}^{+} \mathrm{CD} 93^{+} \mathrm{CD} 24^{+}\right)$as well as the surrogate light chains (CD179a/b); some cells also expressed BP-1 (early pre B cells) but not intracellular heavy chain. Developing $B$ cells undergo heavy chain rearrangement during the transition to pro-B cells and VDJ-rearrangement before becoming pre-B cells. 
A

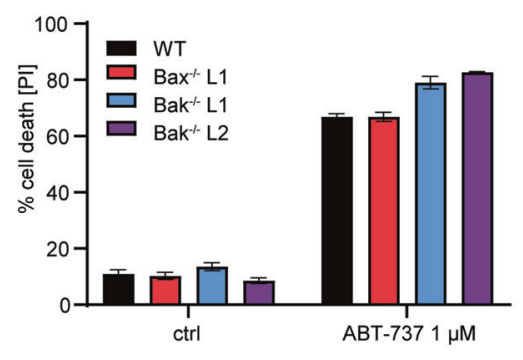

B

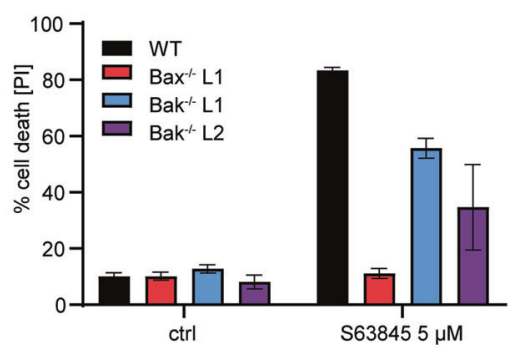

C

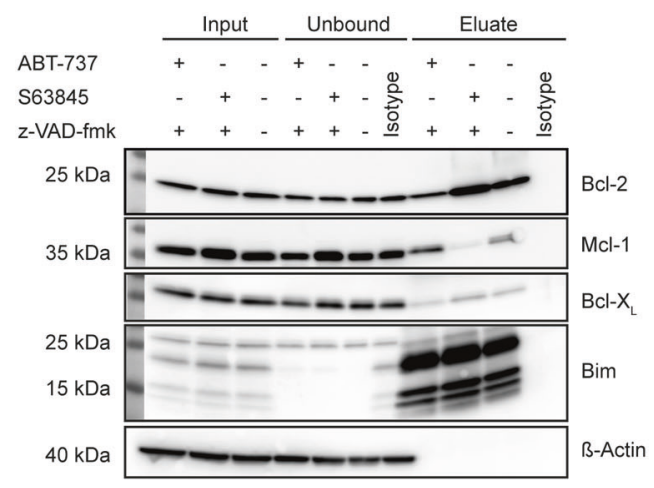

Fig. 3 Role of Bax vs. Bak and interactions of Bim in FL-P cells. A, B FLP-cells of the indicated genotypes were treated with Bcl-2-family inhibitors at the concentrations indicated (controls were incubated with DMSO) for $24 \mathrm{~h}$ and analyzed by propidium staining and flow cytometry. Shown are mean values/SD of three independent experiments. Data are individual points of the titrations shown in Supplementary Fig. S4. C Immunoprecipitation of Bim and Bim-interacting Bcl-2-family proteins. FL-P cells (wt) were incubated with $1 \mu \mathrm{M}$ ABT-737 or $3 \mu \mathrm{M}$ S63845 plus $20 \mu \mathrm{M}$ z-VAD-fmk or DMSO for $4 \mathrm{~h}$. Input and unbound are equivalent protein amounts; eluate was the complete IP-product. Proteins were separated by SDS-Page and transferred to a PVDF membrane. Membranes were probed for Bcl-2 proteins as indicated. Blots are representative of three independent experiments.

A

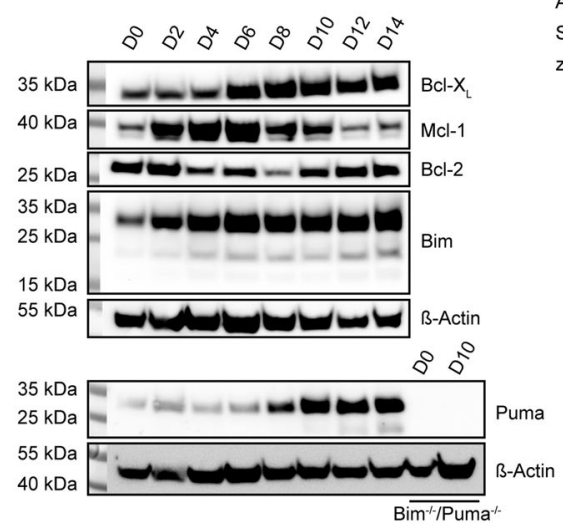

B

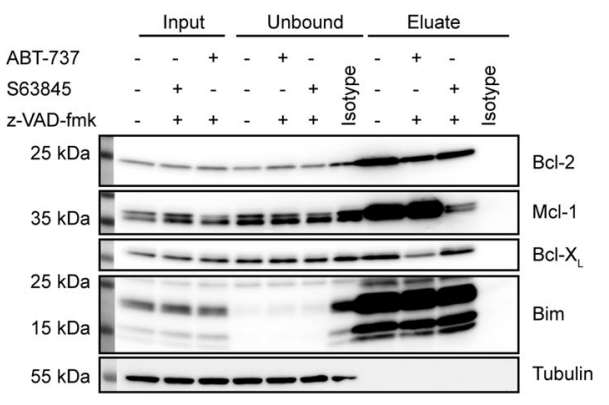

Fig. 4 Changes in expression of Bcl-2-family proteins and Bim-interactions during differentiation of early B cells. A Western blot analysis of endogenous Bcl-2 protein levels in wt Hoxb8-FLT3 cells differentiating in vitro. FL-D cells were cultured in the presence of IL-7, FLT3L and SCF for 14 days. Samples were taken every two days, lysed and analyzed by SDS-PAGE and western blotting. Membranes were probed for Bcl-2 family proteins as indicated. Shown are two different membranes from the same cell lysates. B Analysis of Bim-interacting Bcl-2-family proteins. FL-D cells (differentiated for $14 \mathrm{~d}$ as above) were incubated with either $1 \mu \mathrm{M}$ ABT-737 or $3 \mu \mathrm{M}$ S63845 in the presence of $20 \mu \mathrm{M} z-$ VAD-fmk or DMSO. Bim was immunoprecipitated (isotype, isotype control antibody). Samples were processed for western blotting. Input and unbound are equivalent protein amounts; eluate was the complete IP-product. Membranes were probed for Bcl-2 proteins as indicated. All blots are representative of three separate experiments. 

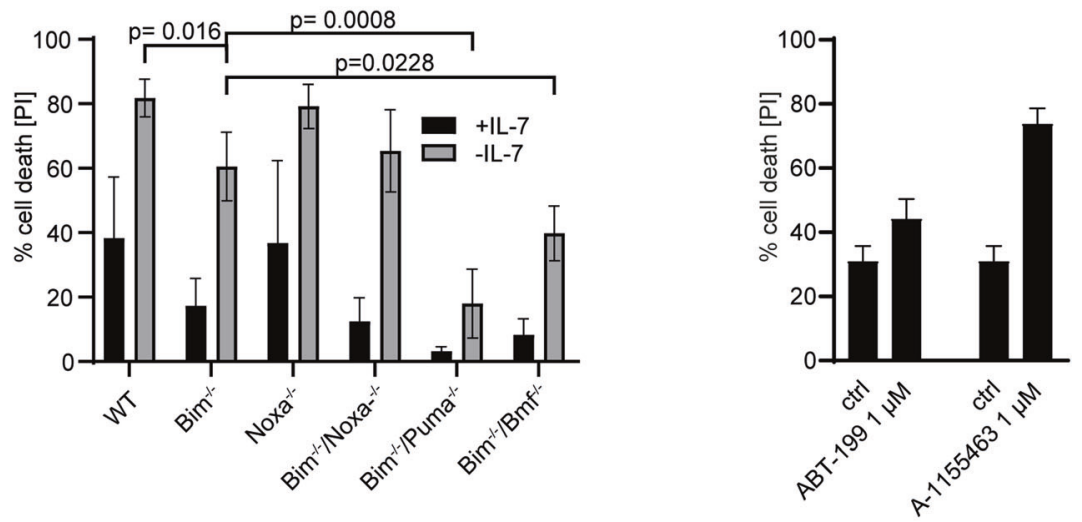

C

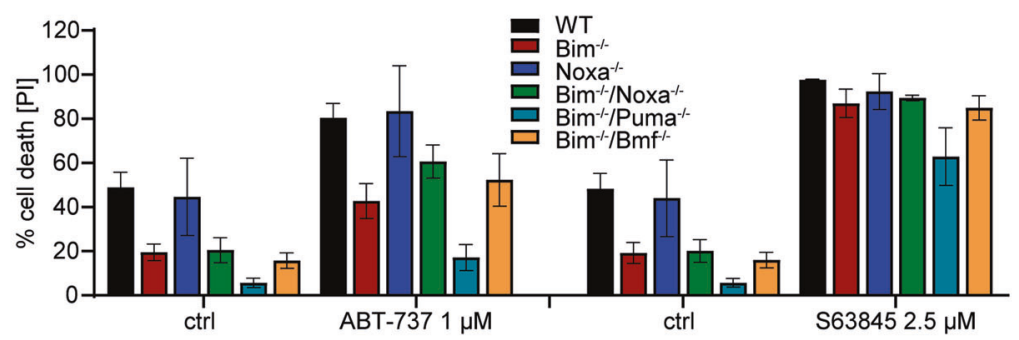

Fig. 5 Role of BH3-only proteins in apoptosis induced by inhibition of anti-apoptotic Bcl-2-proteins in FL-D cells. A FL-D cells (10 5 d14 in vitro differentiated cells) of the indicated genotypes were incubated in presence or absence of IL-7. Cell viability was determined after $24 \mathrm{~h}$ by propidium iodide staining and flow cytometry. Significance levels were calculated using unpaired $t$-test. B FL-D cells ( $10^{5}$ d 14 in vitro differentiated cells) were treated with $1 \mu \mathrm{M}$ ABT-199 or $1 \mu \mathrm{M}$ A-1155463. Cell viability was determined after $24 \mathrm{~h}$ by propidium iodide staining and flow cytometry. Shown are the means/SD of three independent experiments. Data are taken from the complete titration shown in Supplementary Fig. S7. C FL-D cells $\left(10^{5} \mathrm{~d} 14\right.$ in vitro differentiated cells) of the indicated genotypes were treated with $1 \mu \mathrm{M}$ ABT-737 or $2.5 \mu \mathrm{M}$ S63845. Cell viability was determined after $24 \mathrm{~h}$ by propidium iodide staining and flow cytometry. Data are means/SD of three independent experiments. Data are individual points of the titrations shown in Supplementary Fig. S7. Supplementary Information is available at Cell Death and Differentiation's website.

The cells we use here were mostly at the pro-B cell stage. There was no major phenotypic change after day 11 (Supplementary Fig. S6) but the cells kept expanding. The expression of Bim was strongly upregulated during the first 4 days and remained at comparably high levels from then on (Fig. 4A). Puma was strongly up-regulated around day 10 (late pro $B$ cell stage). The expression of Bcl- $X_{L}$ was relatively low initially and increased substantially between days 4 and 6. Great dynamic was however seen in the regulation of $\mathrm{Mcl}-1$ and Bcl-2-expression. Both proteins showed similar expression levels at progenitor stage and after about 12 days of differentiation. In between, however, here was a drastic up- and down regulation of $\mathrm{MCl}-1$ protein between days 2 and 6 . BCl-2, on the other hand, was transiently down-regulated between days 4 and 8 (Fig. 4A). The regulation of $\mathrm{Mcl}-1$ was also seen in Noxa-deficient cells (Supplementary Fig. S7A). We were unable to obtain a clear staining for Mcl1 , but intracellular staining and flow cytometry of murine bone marrow confirmed differences in Bcl-2-expression between the various stages of B cell-development (Supplementary Fig. S7B).

\section{Role of Bcl-2-family members in early B cells}

We differentiated the cells to test whether differentiation status (differentiation from the LMPP to the pro-B cell stage) affected the role of $\mathrm{Bcl}$-2-proteins in apoptosis sensitivity. It was noticeable that in differentiated cells more anti-apoptotic protein was coimmunoprecipitated with Bim (Fig. 4B; compare IP-product with input in Fig. $4 \mathrm{~B}$ and Fig. $3 \mathrm{C}$ ), suggesting that Bim was increasingly complexed by anti-apoptotic Bcl-2-family proteins. We then tested apoptosis sensitivity in cells differentiated as above for 14 days
(FL-D cells). Cells underwent rapid cell death upon IL-7-withdrawal. Loss of Bim provided some protection, as found previously for $\mathrm{T}$ cell progenitors [21]. Intriguingly, Noxa had lost all importance with regard to factor withdrawal during differentiation even on a Bim-deficient background, but Puma had acquired a prominent role: in the absence of Bim, Puma-deficiency provided strong protection, similar to the role previously identified in activated T cells [22]. The loss of Bmf on a Bim-deficient background also provided some protection (Fig. 5A).

Although $\mathrm{BCl}$-2-levels were only slightly reduced in FL-D compared to FL-P cells, Bcl-2-inhibition had little pro-apoptotic effect while inhibition of $\mathrm{BCl}-\mathrm{X}_{\mathrm{L}}$ was a strong pro-apoptotic signal (Fig. 5B), reflected by a strong up-regulation of the protein (Fig. 4). Loss of Bim had some protective effect against ABT-737-induced cell death while Bim/Puma-deficiency gave strong protection (Fig. 5C). Cell death induced by Mcl-1-inhibition again did not depend on Bim, but the combined loss of Bim and Puma afforded some protection (Fig. 5C; Supplementary Fig. S7). Substantial changes in $\mathrm{Bcl}$-2-protein function during differentiation from LMPP cells towards B cells thus include the loss of the importance of Noxa, the gain in importance of Puma, a somewhat smaller importance of Bim itself in ABT-737-induced apoptosis, and changes in the relevance of $\mathrm{BCl}-2$ and $\mathrm{BCl}-\mathrm{X}_{\mathrm{L}}$.

\section{DISCUSSION}

Information about the relevance to apoptosis-induction in immune cells had been available for Bim and, in some situations, 
for other BH3-only proteins. Our results identify the importance of Bim specifically for the neutralization of $\mathrm{Mcl}-1$ and assign functions to Noxa and Puma. They further describe unexpectedly strong shifts in the expression of especially anti-apoptotic Bcl-2family proteins during early $B$ cell differentiation as well as partly non-redundant roles of Bax and Bak. Stage-specific expression of $\mathrm{Bcl}$-2-family proteins in culture suggests an intrinsic regulation and a specific role of the individual members of the family. By combining the loss of pro-apoptotic with the chemical neutralization of anti-apoptotic Bcl-2-family proteins, we obtained information about the roles of individual proteins in the network.

Bim is required for full apoptosis in most immune cells. Bim can principally neutralize all anti-apoptotic Bcl-2-proteins and activate Bax and Bak directly. What it actually does upon apoptosis initiation is however not clear. In FL-P cells, Bim was essential to apoptosis induced by inhibition of $\mathrm{BCl}-2$ and $\mathrm{BCl}-\mathrm{X}_{\mathrm{L}}$. In this situation Bax and Bak were redundant, suggesting that Bim can activate either protein. Bim may here either directly activate Bax/ Bak or inactivate $\mathrm{Mcl}-1$. Although it is not possible completely to exclude either possibility, the finding that the addition of a Mcl-1inhibitor induces cell death that is independent of Bim suggests that the function of Bim is the neutralization of $\mathrm{Mcl}-1$. Isolated Noxa-deficiency had a surprisingly strong effect in FL-P cells. Noxa-deficient cells had more Mcl-1-protein, and the higher doses of Mcl-1-inhibitor could compensate for the loss of Noxa. This suggests that the role of Noxa indeed is the regulation of Mcl-1levels. Mouse Noxa differs from human Noxa especially in that it has a second $\mathrm{BH} 3$-domain, although experiments with truncation mutants suggest that only the C-terminal $\mathrm{BH}$-domain is used to inactivate $\mathrm{Mcl}-1$ [23]. There may be additional functional differences to human cells [24]. In the absence of Bim, Mcl-1inhibition required Puma for efficient apoptosis-induction. Because of the critical role of Bax for apoptosis-induction by Mcl-1-inhibition, Puma - perhaps together with Bim - in this situation very likely can activate Bax. In activated T cells, Puma has been reported to have a pro-apoptotic role that is only detectable in the absence of Bim; in developing B cells, Bim- but not Pumadeficiency could to a degree rescue development. No information appears to be available in other cell types. More work will still be required to understand all the mechanics, but the results identify critical and redundant pairings in the interaction of Bcl-2-family proteins. The relative importance of anti-apoptotic proteins in keeping $\mathrm{FL}-\mathrm{P}$ cells alive runs as $\mathrm{Mcl}-1-\mathrm{BCl}-2-\mathrm{BCl}-\mathrm{X}_{\mathrm{L}}$.

An intriguing result of the IP-experiments was that, despite the relevance of Bim for apoptosis-induction, relatively little of the antiapoptotic Bcl-2-proteins were co-precipitated with Bim; the inclusion of $A B T-737$ caused no visible change in the abundance of $\mathrm{Bcl}-2$ or $\mathrm{BCl}-\mathrm{X}_{\mathrm{L}}$ in the fraction not bound to Bim (although some change was seen for $\mathrm{Mcl}-1$ ). We have to allow for experimental imperfections in the sense that complexes may to some degree be sensitive to cell lysis and detergent. It seems a possibility however that most Bim is actually not bound to anti-apoptotic Bcl-2-proteins, and may indeed not be active. We have recently described that Bim can be found in large complexes coordinated by dynein light chain [25], and these complexes may represent inactive 'stores' of Bim. Isolation and characterization of complexes is an important issue, which we have not fully addressed in this study. It is a limitation that we have so far only immuno-precipitated Bim. This showed the surprisingly low amount of binding to anti-apoptotic proteins. Reciprocal IPs, for instance of Mcl-1, will be helpful to understand complex formation within the Bcl-2-family better.

It is notoriously difficult to understand the manifold interactions of pro- and anti-apoptotic Bcl-2-family members and how they change during the induction of apoptosis, either through upstream signals such as factor withdrawal or through the specific inhibition of $\mathrm{Bcl}$-2-like proteins. Approaches such as quantitative proteomic analysis of precipitates and cross-linking mass-spectrometry [26] will in the future be helpful to clarify how these interactions change and may even be able to elucidate whether a BH3-only protein acts through direct activation or through displacement [27]. It may for instance be possible to discover the shift of $\mathrm{Mcl}-1$ (or other antiapoptotic proteins) away from Bim to the binding of Bak.

Comparing early B cells to FL-P cells, Noxa had lost all importance during apoptosis induced by Bcl-2-family inhibition or factor withdrawal. Puma, on the other hand, had considerably gained in relevance, paralleled by the strong up-regulation of the protein. Mcl1 still had the most important anti-apoptotic role but Bcl- $X_{L}$ was now much more important than Bcl-2. Bim itself was expressed more highly in FL-D cells but its importance in apoptosis induction appeared somewhat smaller than its role in FL-P cells.

Bmf, finally, is a BH3-only protein that has, based on experiments with gene-deficient cells, only a limited role in the cells investigated so far, with the most prominent role reported in $B$ cells [9]. Our results confirm this role: an effect of Bmf-loss (in addition to Bim) on factor-induced apoptosis was seen in early B cells but not in LMPP. Bmf however played no role in regulating apoptosis induced by Bcl-2-family-inhibitors. Because of the independence of anti-apoptotic proteins, this is most easily explained by an upstream regulatory effect of factor-withdrawal on Bmf-activity.

One of the striking changes during early B cell differentiation was the transient upregulation of $\mathrm{Mcl}-1$. Mcl-1-expression during $B$ cell development has been measured before on the mRNA-level [28], and no similar change had been observed. Because Mcl-1 is strongly regulated by post-translational signals [29], this is no contradiction but suggests that the effect is due to signals that regulate protein stability. During differentiation in the Hoxb8-model the external stimuli do not change during culture. The data therefore suggest that $\mathrm{Mcl}$-1-regulation occurs as part of the intrinsic differentiation program. A likely signaling pathway is the PI3 kinase/AKT signaling axis, which is a well-established regulator of Mcl-1-stability [30], and which is active during early $B$ cell development [31]. The signals regulating expression of the other $\mathrm{BCl}-2$-family proteins during $\mathrm{B}$ cell development are less clear, but our findings suggest regulation of these proteins through signals that are generated cell autonomously as part of the $B$ cell maturation program. A further intriguing aspect is the difference in susceptibility of FL-P and early B cells when growth factors are removed: in FL-P cells, Noxa plays an important role, in the early B cells Puma was much more important. The different factors to which the cells are 'addicted' may play a role. As in many cases of upstream signals, it is only partially clear how a signal from cytokine receptors, or the signal of their absence reaches mitochondria. Most consistent has been the description of the regulation of $\mathrm{Mcl}-1$-levels through this axis, and indeed this has been found for both FLT-3 ligand [32] (which we used for the FL-P cells) and IL-7 (or other signals through the common gamma chain) [33], the survival stimulus in our B cell cultures. Mcl-1-regulation itself is very complex and involves transcriptional and post-translational modifications [34]. Noxa is one major regulatory molecule of Mcl-1levels [16], so the regulation of cell death upon FLT3-ligandwithdrawal in FL-P cells, where Noxa plays a major role, likely occurs through this pathway. How apoptosis is regulated upon withdrawal of IL-7 is unclear. Mcl-1 may be degraded by numerous other mechanisms, and this may for instance allow the activation of Bak [35]. Differences and potential common regulation in these situations will require a more detailed study. The significant role of Puma in apoptosis-induction in early B cells but not in FL-P cells correlated with its substantial upregulation. This regulation is intriguing: Puma is best known as a p53-target $[36,37]$ but can also be regulated by other transcriptional mechanisms. NF-KB in particular can drive Puma transcription [38] and is a likely contributor during B cell development.

Through the large number of proteins, the differential expression and over-lapping functions, the regulation of $\mathrm{Bcl}$-2-protein activity is extremely challenging to map. Our results add information about the molecular role of these proteins in the 
orchestration of apoptosis in a cellular model that probably reflects differentiation stages of murine lymphoid cells. To some extent, they suggest new hypotheses that will need to be tested. By the broad testing of pro-apoptotic proteins through genedeficiency, combined with the specific inhibition of anti-apoptotic $\mathrm{Bcl}$-2-proteins, they identify molecular roles of individual proteins as well as combinations of family members. The knowledge of the roles of individual $\mathrm{Bcl}-2$-family proteins in lymphoid progenitor cells may inform studies of Bcl-2-family inhibitors on apoptosis induction in malignant lymphoid cells and eventually the use of these inhibitors in the clinic [39].

\section{MATERIAL AND METHODS}

\section{Generation of FLT3-driven LMPP lines}

LMPP cell lines (FL-P) were established from mouse bone marrow of the respective gene-deficient mice as reported [13] (the single-deficient mice have been described $[6,9,40,41]$. The crosses of mice deficient in Bim and other $\mathrm{BH} 3$-only proteins were conducted by $\mathrm{Dr}$ Andreas Villunger, Innsbruck, who kindly provided the bone marrow). Briefly, bone marrow cells were infected with a retrovirus expressing oestrogen-regulated Hoxb8 (generously provided by Hans Häcker, Salt Lake City). Cells were expanded in the presence of oestrogen and FLT3L. For Bim-deficient cells, several cell lines were initially established from several mice and tested for differences in survival and differentiation; no substantial differences were seen. Cells were cultured in VLE RPMI medium supplemented with 10\% FCS (Gibco), 1\% Pen-Strep (), 1\% GlutaMax (Thermo Fisher), $50 \mu \mathrm{M}$ B-mercaptoethanol (Gibco), $10 \mu \mathrm{M} \beta$-estradiol (Sigma Aldrich) and $5 \%$ FLT3L-containing supernatant from a transgenic B16 mouse melanoma cell line

\section{In vitro differentiation of early $B$ cells}

Hoxb8 FLP cells were washed twice in PBS with $1 \%$ FCS to remove $\beta$-estradiol. Cells $\left(4 \times 10^{5}\right.$ cells in $2 \mathrm{ml}$ in 6 -well plates) were resuspended in B-cell medium: DMEM, high glucose, (Gibco) + 10\% FCS (Gibco) + $50 \mu \mathrm{M}$ ßmercaptoethanol (Gibco) $+1 \%$ Pen-Strep (Gibco) + 1\% sodium pyruvate (Gibco) $+15 \mathrm{ng} / \mathrm{ml}$ recombinant murine IL-7 (Peprotech) $+30 \mathrm{ng} / \mathrm{ml}$ recombinant murine $\mathrm{FLT3L}+7.5 \%$ CHO-SCF-containing supernatant and grown for various times. Cells were resuspended in fresh medium on day 2 , split into two wells on day 3 , then split every 2-3 days with addition of fresh medium. For cell death assays, cells were harvested on day 14 of differentiation. Live cells were separated using the MACS Dead Cell Removal kit (Miltenyi Laboratories).

\section{Cell death assays}

FL-P or FL-D cells were plated in 24-well plates $\left(10^{5}\right.$ cells in $500 \mu \mathrm{l} \mathrm{Hoxb8}$ progenitor or B cell medium) and treated with etoposide (Sigma Aldrich) or the inhibitors ABT-737, ABT-199, A-1155463 (Selleckchem) or S53845 (ApexBio) as indicated. For analysis of cell death induced by factor withdrawal, cells were washed and plated without FLT3L (FL-P-cells) or IL7 (FL-D-cells). At various time points, cells were collected in PBS/4\% FCS. Propidium iodide (Sigma Aldrich) was added immediately prior to analysis by flow cytometry (FACS-Calibur, Becton Dickinson). In some experiments, annexin V-propidium iodide staining was used for quantification of apoptosis. Cell were washed with annexin V-binding buffer (eBioscience) and stained with annexin V-FITC (1:20, BD Pharmingen) and PI $(5 \mu \mathrm{g} / \mathrm{ml})$ for $20 \mathrm{~min}$ at $4^{\circ} \mathrm{C}$ followed by flow cytometry analysis (FACS Calibur). For staining of active caspase- 3 , cells were fixed in $2 \%$ paraformaldehyde and permeabilized with $0.5 \%$ saponin (Sigma-Aldrich). Cells were incubated with anti-active caspase-3 (BD Pharmingen) in $\mathrm{PBS} / 0.5 \% \mathrm{BSA} / 0.5 \%$ saponin for $30 \mathrm{~min}$, stained with anti-rabbit-Alexa-Fluor488 (Dianova $\mathrm{GmbH}$, Hamburg, Germany) for $30 \mathrm{~min}$ and analyzed by flow cytometry (FACS Calibur). Routinely, three biological replicates were performed. Further replicates were done depending on the statistical distribution of the values.

\section{Western blotting}

FL-P or FL-D cells $\left(5 \times 10^{6}\right)$ were washed and lysed in $100 \mu$ lysis buffer BOLT lysis buffer, sonicated and loaded on BOLT 4-12\% Bis-Tris precast gels (ThermoFisher). Proteins were transferred to nitrocellulose membranes by wet transfer, and specific proteins were detected with antibodies against Bim (Cell Signaling, clone C3435), Noxa (Abcam, polyclonal), Puma (Cell Signaling, polyclonal), Mcl-1 (Rockland, polyclonal and BioLegend, W16014A [42]), BCl-2 (BioLegend, 3F11), BCl- $\mathrm{X}_{\mathrm{L}}$ (Cell
Signaling, 54H6), B-Actin (Sigma Aldrich, AC-15), GAPDH (Millipore, 6C5), aTubulin (Sigma Aldrich, DM 1A). Secondary antibodies used were goat-antirabbit (Millipore), goat-anti-mouse Millipore or goat-anti-rat (Cell Signaling) coupled to peroxidase. Signals were detected with ECL Pico/Prime/Femto using a chemiluminescence detection system (Intas Detection Systems).

\section{Immunoprecipitation}

Cell pellets $\left(4.5 \times 10^{7}\right.$ cells per sample) were lysed in $750 \mu$ lysis buffer: $20 \mathrm{mM}$ Tris- $\mathrm{HCl}$ (Tris, Sigma Aldrich; $\mathrm{HCl}$, Carl Roth), $150 \mathrm{mM} \mathrm{NaCl}$ (Carl Roth), 10\% Glycerol (Carl Roth), 1\% Triton X-100 (Sigma Aldrich), 1X protease inhibitor cocktail (Roche) on ice and centrifuged for $10 \mathrm{~min}$ at $10.000 \times g$. Supernatants were transferred to a new tube. Protein concentrations were measured by Braford assay (BioRad), and $1500 \mu \mathrm{g}$ of protein were used for IP. Bim-antibody (Cell Signaling, C3435), or isotype control antibody (mouse mAb $\mathrm{lgG} 1 \mathrm{k}, 2.5 \mathrm{mg} / \mathrm{ml}$ ) Cell Signaling, G3A1) was added to protein and Agarose $\mathrm{G}$ beads (Millipore Sigma, $30 \mu \mathrm{l}$ slurry per IP). Samples were incubated for $4 \mathrm{~h}$ at $4^{\circ} \mathrm{C}$ with overhead rotation. After incubation, reactions were centrifuged, unbound fraction was collected. IPproducts were washed $1 \mathrm{x}$ with $15 \mathrm{ml}$ washing buffer and subsequently washed three times with $350 \mu \mathrm{l}$ washing buffer. Proteins were eluted by boiling in $3 \mathrm{x}$ Laemmli buffer $\left(95^{\circ} \mathrm{C}, 5 \mathrm{~min}\right)$. For input and unbound samples, $50 \mu \mathrm{g}$ samples (for unbound fraction, 1/30) were used per lane. Samples were run on SDS-PAGE as above and blotted onto PVDFmembranes. Detection was carried out as described above.

\section{Flow cytometry}

For differentiation of differentiating cells, cells were harvested, washed and stained with the following antibodies: CD44-APC (BD, IM7), CD25-FITC (eBioscience, PC61.5), CD93-APC (eBioscience, AA4.1), B220-FITC (BD, RA3-6B2), CD19-APC (eBioscience, 1D3), IgM-PE (eBioscience, eB121-15F9), B220-APC (eBioscience, RA3-6B2), Thy1.2-FITC (eBioscience, 30-H12), CD135-APC (BioLegend, A2F10), CD127-PE (eBioscience, A7R34), BP-1-PE (eBioscience, 6C3), CD24-APC-Cy7 (eBioscience, M1/69), CD43-APC (BioLegend, S11). For intracellular staining, cells were permeabilized using $0.05 \%$ saponin and stained with antibodies against CD79a-APC (BioLegend, F11-172), CD79b-FITC (BioLegend, HM79-12), CD179a-BV421 (BioLegend, R3), CD179b-BB700 (BioLegend, LM34). For the Bcl-2-specific stain, the Foxp3 staining kit (ThermoFisher) was used. As antibody, Bcl-2AF647 (BioLegend, 10C4) was used. Analysis was carried out using a FACS Canto II cytometer (Beckton Dickinson).

\section{REFERENCES}

1. Czabotar PE, Lessene G, Strasser A, Adams JM. Control of apoptosis by the BCL-2 protein family: implications for physiology and therapy. Nat Rev Mol cell Biol. 2014;15:49-63.

2. Chipuk JE, Moldoveanu T, Llambi F, Parsons MJ, Green DR. The BCL-2 family reunion. Mol Cell. 2010;37:299-310.

3. Ogilvy S, Metcalf D, Print CG, Bath ML, Harris AW, Adams JM. Constitutive BCl-2 expression throughout the hematopoietic compartment affects multiple lineages and enhances progenitor cell survival. Proc Natl Acad Sci USA. 1999;96:14943-8.

4. Carrington EM, Tarlinton DM, Gray DH, Huntington ND, Zhan Y, Lew AM. The life and death of immune cell types: the role of $\mathrm{BCL}-2$ anti-apoptotic molecules. Immunol Cell Biol. 2017;95:870-7.

5. Carrington EM, Zhan Y, Brady JL, Zhang JG, Sutherland RM, Anstee NS, et al. Antiapoptotic proteins $B C L-2, M C L-1$ and $A 1$ summate collectively to maintain survival of immune cell populations both in vitro and in vivo. Cell Death Differ. 2017;24:878-88.

6. Bouillet $P$, Metcalf $D$, Huang DC, Tarlinton DM, Kay TW, Kontgen F, et al. Proapoptotic $\mathrm{BCl}-2$ relative Bim required for certain apoptotic responses, leukocyte homeostasis, and to preclude autoimmunity. Science. 1999;286:1735-8.

7. Pellegrini $M$, Belz G, Bouillet $P$, Strasser A. Shutdown of an acute $T$ cell immune response to viral infection is mediated by the proapoptotic Bcl-2 homology 3-only protein Bim. Proc Natl Acad Sci USA. 2003;100:14175-80.

8. Bauer A, Villunger A, Labi V, Fischer SF, Strasser A, Wagner H, et al. The NF-kappaB regulator $\mathrm{BCl}-3$ and the $\mathrm{BH} 3$-only proteins $\mathrm{Bim}$ and Puma control the death of activated T cells. Proc Natl Acad Sci USA. 2006;103:10979-84.

9. Labi V, Erlacher M, Kiessling S, Manzl C, Frenzel A, O'Reilly L, et al. Loss of the BH3only protein Bmf impairs $B$ cell homeostasis and accelerates gamma irradiationinduced thymic lymphoma development. J Exp Med. 2008;205:641-55.

10. Huntington ND, Puthalakath $H$, Gunn P, Naik E, Michalak EM, Smyth MJ, et al. Interleukin 15-mediated survival of natural killer cells is determined by interactions among Bim, Noxa and Mcl-1. Nat Immunol. 2007;8:856-63. 
11. Eitz Ferrer P, Potthoff S, Kirschnek S, Gasteiger $G$, Kastenmuller W, Ludwig H, et al. Induction of Noxa-mediated apoptosis by modified vaccinia virus Ankara depends on viral recognition by cytosolic helicases, leading to IRF-3/IFN-betadependent induction of pro-apoptotic Noxa. PLoS Pathog. 2011;7:e1002083.

12. Adolfsson J, Mansson R, Buza-Vidas N, Hultquist A, Liuba K, Jensen CT, et al. Identification of Flt3+ lympho-myeloid stem cells lacking erythromegakaryocytic potential a revised road map for adult blood lineage commitment. Cell. 2005;121:295-306.

13. Redecke V, Wu R, Zhou J, Finkelstein D, Chaturvedi V, High AA, et al. Hematopoietic progenitor cell lines with myeloid and lymphoid potential. Nat Methods. 2013;10:795-803.

14. Argiropoulos B, Humphries RK. Hox genes in hematopoiesis and leukemogenesis. Oncogene. 2007;26:6766-76.

15. Wang GG, Calvo KR, Pasillas MP, Sykes DB, Hacker H, Kamps MP. Quantitative production of macrophages or neutrophils ex vivo using conditional Hoxb8. Nat Methods. 2006;3:287-93.

16. Czabotar PE, Lee EF, van Delft MF, Day CL, Smith BJ, Huang DC, et al. Structural insights into the degradation of $\mathrm{Mcl}-1$ induced by $\mathrm{BH} 3$ domains. Proc Natl Acad Sci USA. 2007;104:6217-22.

17. Souers AJ, Leverson JD, Boghaert ER, Ackler SL, Catron ND, Chen J, et al. ABT-199, a potent and selective $B C L-2$ inhibitor, achieves antitumor activity while sparing platelets. Nat Med. 2013;19:202-8.

18. Tao ZF, Hasvold L, Wang L, Wang X, Petros AM, Park CH, et al. Discovery of a potent and selective BCL-XL inhibitor with in vivo activity. ACS Med Chem Lett. 2014;5:1088-93.

19. Chen L, Willis SN, Wei A, Smith BJ, Fletcher Jl, Hinds MG, et al. Differential targeting of prosurvival $\mathrm{BCl}-2$ proteins by their $\mathrm{BH} 3$-only ligands allows complementary apoptotic function. Mol Cell. 2005;17:393-403.

20. Kotschy A, Szlavik Z, Murray J, Davidson J, Maragno AL, Le Toumelin-Braizat G, et al. The MCL1 inhibitor S63845 is tolerable and effective in diverse cancer models. Nature. 2016;538:477-82.

21. Pellegrini M, Bouillet P, Robati M, Belz GT, Davey GM, Strasser A. Loss of Bim increases $T$ cell production and function in interleukin 7 receptor-deficient mice. J Exp Med. 2004;200:1189-95.

22. Erlacher M, Labi V, Manzl C, Bock G, Tzankov A, Hacker G, et al. Puma cooperates with Bim, the rate-limiting $\mathrm{BH} 3$-only protein in cell death during lymphocyte development, in apoptosis induction. J Exp Med. 2006:203:2939-51.

23. Weber A, Auslander D, Hacker G. Mouse Noxa uses only the C-terminal BH3domain to inactivate Mcl-1. Apoptosis. 2013;18:1093-105.

24. Ploner $C$, Kofler R, Villunger A. Noxa: at the tip of the balance between life and death. Oncogene. 2008;27:S84-92.

25. Singh PK, Roukounakis A, Frank DO, Kirschnek S, Das KK, Neumann S, et al. Dynein light chain 1 induces assembly of large Bim complexes on mitochondria that stabilize Mcl-1 and regulate apoptosis. Genes Dev. 2017;31:1754-69.

26. Leitner A, Bonvin A, Borchers CH, Chalkley RJ, Chamot-Rooke J, Combe CW, et al. Toward increased reliability, transparency, and accessibility in cross-linking mass spectrometry. Structure. 2020;28:1259-68.

27. Llambi F, Moldoveanu T, Tait SW, Bouchier-Hayes L, Temirov J, McCormick LL, et al. A unified model of mammalian BCL-2 protein family interactions at the mitochondria. Mol Cell. 2011;44:517-31.

28. Vikstrom IB, Slomp A, Carrington EM, Moesbergen LM, Chang C, Kelly GL, et al. MCL-1 is required throughout B-cell development and its loss sensitizes specific B-cell subsets to inhibition of BCL-2 or BCL-XL. Cell Death Dis. 2016;7:e2345.

29. Mojsa B, Lassot I, Desagher S. Mcl-1 ubiquitination: unique regulation of an essential survival protein. Cells. 2014;3:418-37.

30. Maurer U, Charvet C, Wagman AS, Dejardin E, Green DR. Glycogen synthase kinase-3 regulates mitochondrial outer membrane permeabilization and apoptosis by destabilization of MCL-1. Mol Cell. 2006;21:749-60.

31. Abdelrasoul $\mathrm{H}$, Werner $\mathrm{M}$, Setz $\mathrm{CS}$, Okkenhaug $\mathrm{K}$, Jumaa H. PI3K induces B-cell development and regulates B cell identity. Sci Rep. 2018;8:1327.

32. Dolence JJ, Gwin K, Frank E, Medina KL. Threshold levels of Flt3-ligand are required for the generation and survival of lymphoid progenitors and B-cell precursors. Eur J Immunol. 2011;41:324-34.

33. Opferman JT, Letai A, Beard C, Sorcinelli MD, Ong CC, Korsmeyer SJ. Development and maintenance of $B$ and T lymphocytes requires antiapoptotic MCL-1. Nature. 2003;426:671-6.

34. Senichkin VV, Streletskaia AY, Gorbunova AS, Zhivotovsky B, Kopeina GS. Saga of Mcl-1: regulation from transcription to degradation. Cell Death Differ. 2020;27:405-19.

35. Senft D, Weber A, Saathoff F, Berking C, Heppt MV, Kammerbauer C, et al. In nontransformed cells Bak activates upon loss of anti-apoptotic Bcl-XL and Mcl-1 but in the absence of active BH3-only proteins. Cell Death Dis. 2015;6:e1996.

36. Nakano K, Vousden KH. PUMA, a novel proapoptotic gene, is induced by $\mathrm{p} 53$. Mol Cell. 2001;7:683-94.
37. Yu J, Zhang L, Hwang PM, Kinzler KW, Vogelstein B. PUMA induces the rapid apoptosis of colorectal cancer cells. Mol Cell. 2001;7:673-82.

38. Wang P, Qiu W, Dudgeon C, Liu H, Huang C, Zambetti GP, et al. PUMA is directly activated by NF-kappaB and contributes to TNF-alpha-induced apoptosis. Cell Death Differ. 2009;16:1192-202.

39. Merino D, Kelly GL, Lessene G, Wei AH, Roberts AW, Strasser A. BH3-mimetic drugs: blazing the trail for new cancer medicines. Cancer Cell. 2018;34:879-91.

40. Villunger A, Michalak EM, Coultas L, Mullauer F, Bock G, Ausserlechner MJ, et al. p53- and drug-induced apoptotic responses mediated by $\mathrm{BH} 3$-only proteins Puma and Noxa. Science. 2003;302:1036-8.

41. Lindsten T, Ross AJ, King A, Zong WX, Rathmell JC, Shiels HA, et al. The combined functions of proapoptotic Bcl-2 family members bak and bax are essential for normal development of multiple tissues. Mol Cell. 2000;6:1389-99.

42. Vier J, Groth $M$, Sochalska M, Kirschnek S. The anti-apoptotic Bcl-2 family protein A1/Bfl-1 regulates neutrophil survival and homeostasis and is controlled via PI3K and JAK/STAT signaling. Cell Death Dis. 2016;7:e2103.

\section{ACKNOWLEDGEMENTS}

We thank Dr Andreas Villunger for the kind gift of bone marrow from gene-deficient mice, Dr Hans Häcker for providing the Hoxb8-vectors and Dr Aparna Shenoy for help in establishing the cell lines.

\section{AUTHOR CONTRIBUTIONS}

CK and AM performed experiments. CK and SK developed methodology. CK, AM, SK and $\mathrm{GH}$ analyzed data. GH developed study concept. SK supervised the experimental work. CK, SK and GH wrote manuscript. All authors read and approved the final manuscript.

\section{FUNDING}

This work was supported by the Deutsche Forschungsgemeinschaft (DFG, grant HA 2128/19-1). Open Access funding enabled and organized by Projekt DEAL.

\section{COMPETING INTERESTS}

The authors declare no competing interests.

\section{ETHICS STATEMENT}

The study did not require an ethics statement.

\section{ADDITIONAL INFORMATION}

Supplementary information The online version contains supplementary material available at https://doi.org/10.1038/s41419-021-04079-8.

Correspondence and requests for materials should be addressed to Georg Häcker

Reprints and permission information is available at http://www.nature.com/ reprints

Publisher's note Springer Nature remains neutral with regard to jurisdictional claims in published maps and institutional affiliations.

pen Access This article is licensed under a Creative Commons Attribution 4.0 International License, which permits use, sharing, adaptation, distribution and reproduction in any medium or format, as long as you give appropriate credit to the original author(s) and the source, provide a link to the Creative Commons license, and indicate if changes were made. The images or other third party material in this article are included in the article's Creative Commons license, unless indicated otherwise in a credit line to the material. If material is not included in the article's Creative Commons license and your intended use is not permitted by statutory regulation or exceeds the permitted use, you will need to obtain permission directly from the copyright holder. To view a copy of this license, visit http://creativecommons. org/licenses/by/4.0/.

(c) The Author(s) 2021 